\title{
Design-Build: A Real-World Experimental Pedagogy for Architectural Education
}

\section{HONGXI YIN}

Washington University in St. Louis

\section{JIAN ZHU}

Washington University in St. Louis

In 2016, Team WashU was awarded a $\$ 50,000$ teaching grant from the Prestress/Precast Concrete Institute (PCI) and a $\$ 300,000$ start-up grant from the Office of Chancellor Mark S. Wrighton of Washington University in St. Louis to develop a two-year design studio and seminar courses based on the U.S. Solar Decathlon student competition. The Solar Decathlon series of architectural design studios were part of an academic program closely collaborated with building industry sponsors. This program created new learning networks that combine education and research activities into a holistic, valuable hands-on student design experience. More than 100 WashU architectural students were involved at different stages, including the collaborative design and building process of a solar decathlon house. The project provided our students' unique opportunities for explorations of high-performance precast concrete designs at an advanced level of creative inquiry, design integration, and technical resolution through a systematic approach. In Fall 2017 we delivered one of the most visually appealing, affordable, comfortable, sustainable, and energy-efficient homes for the Solar Decathlon competition. This project was an excellent demonstration of how prefabricated, self-sufficient, and resilient houses can mitigate climate change. The Solar Decathlon house of Team WashU, the Crete House, was awarded the second place in architectural design in the 2017 U.S. Solar Decathlon competition.
BAOYUE WANG

Washington University in St. Louis 


\section{7th ACSA Annual Meeting Project}

Design-Build: A Real-World Experimental Pedagogy for Architectural Education Crete House: Solar Decathlon 2017 Team WashU
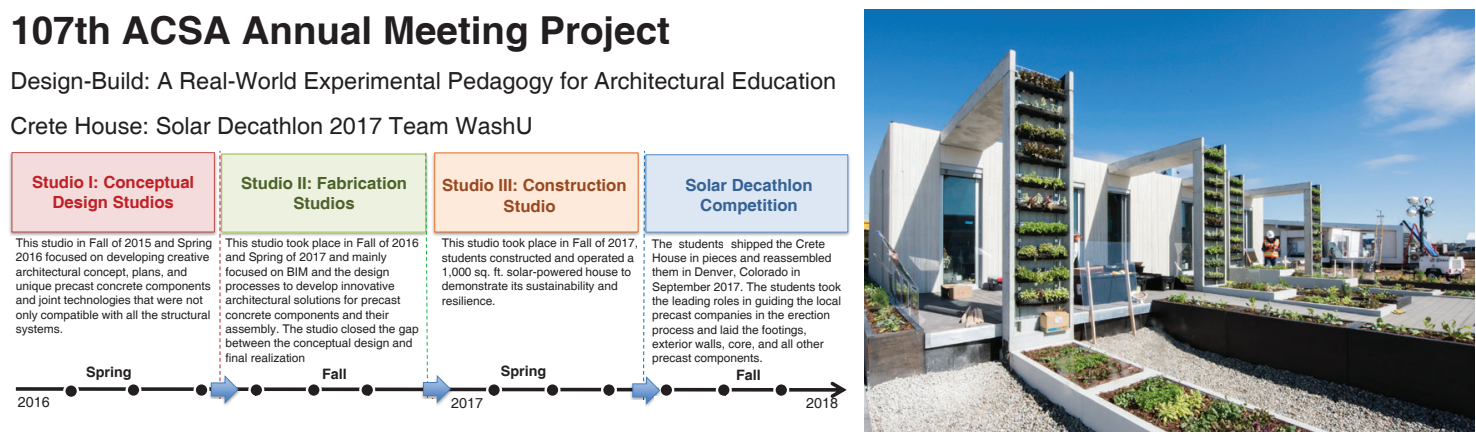

Pedagogy - Construction design

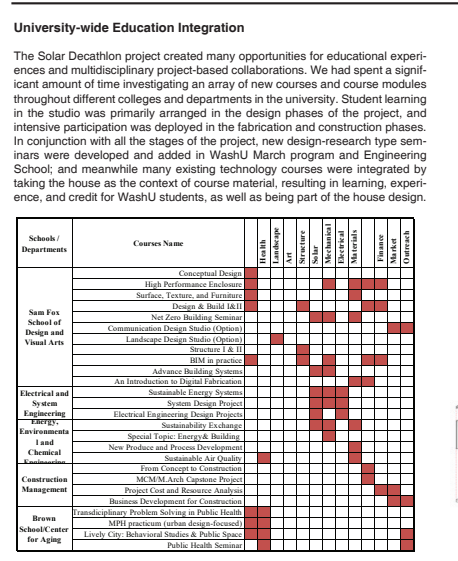

Fabrication - Student Rubber Mold Making

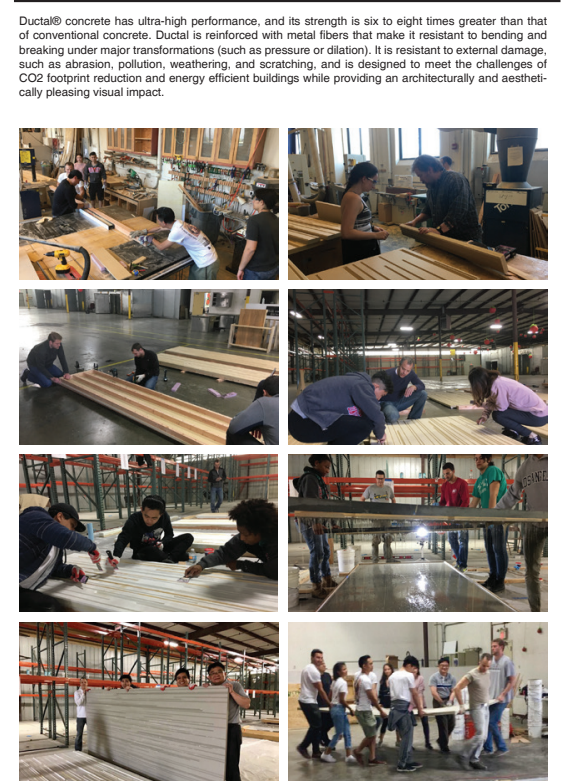

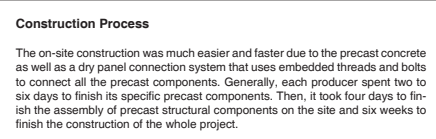

.
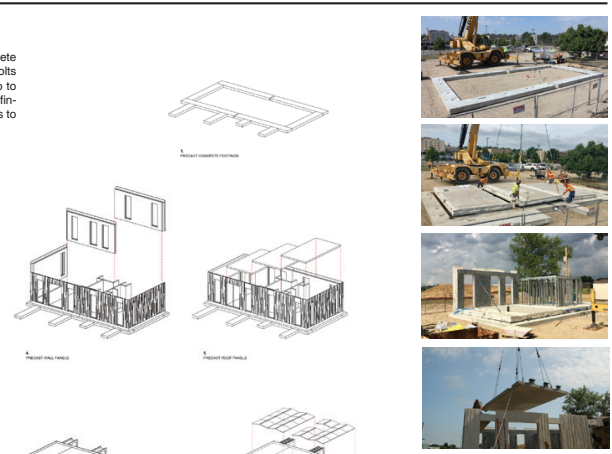

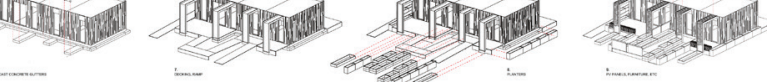

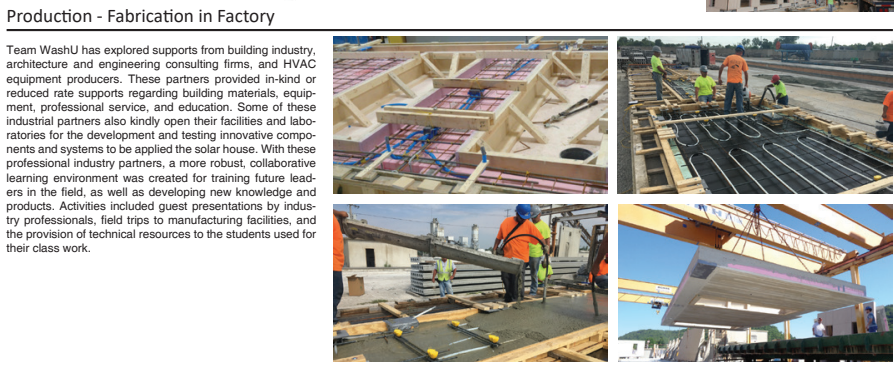

Practice - Construction Led by Student
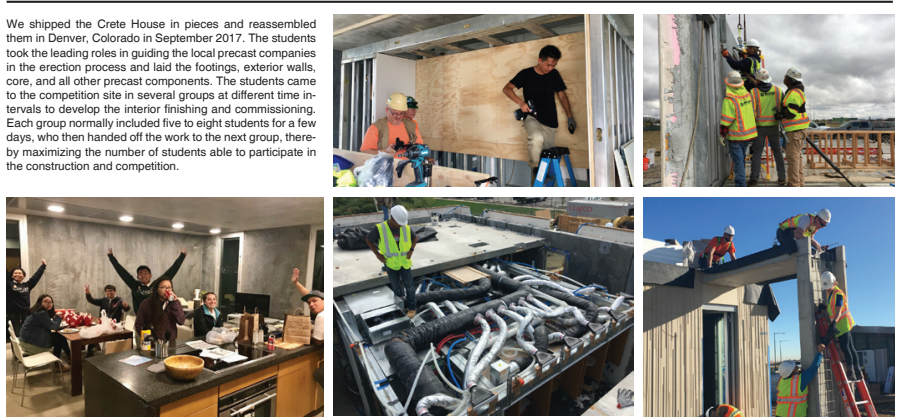

Innovation - Sustainability and Resillience

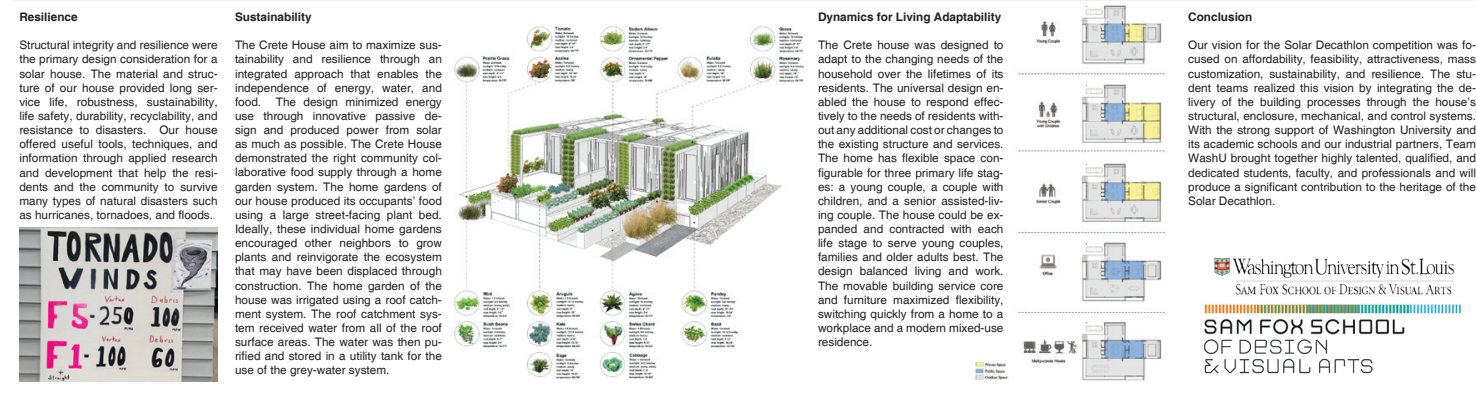

